\title{
Malaria Control Strategy Among Members of American University of Nigeria Yola
}

\author{
Nwambo Joshua Chidiebere ${ }^{1,}$, , Eappen Philip ${ }^{1}$, Joseph Sairah Figgi ${ }^{1}$, Agbele Theresa Onobhase ${ }^{2}$ \\ ${ }^{1}$ AUN Clinic, American University of Nigeria, Yola, Nigeria \\ ${ }^{2}$ Nursing Department, Federal Medical Center, Asaba, Nigeria
}

Email address:

nwamboj@gmail.com (N. J. Chidiebere)

${ }^{*}$ Corresponding author

\section{To cite this article:}

Nwambo Joshua Chidiebere, Eappen Philip, Joseph Sairah Figgi, Agbele Theresa Onobhase. Malaria Control Strategy Among Members of American University of Nigeria Yola. Science Journal of Public Health. Vol. 4, No. 6, 2016, pp. 440-444. doi: 10.11648/j.sjph.20160406.14

Received: September 1, 2016; Accepted: September 12, 2016; Published: October 8, 2016

\begin{abstract}
Malaria is well known public health menace in Nigeria with huge economic and social cost especially in institutions or university community, where it accounts for more outpatients' visits than any other cause, yet the incidence of malaria is on the rise. This study examined the individual control strategy for malaria infestation among members of American University of Nigeria Community. The study utilized a descriptive survey approach. An internet base self-structured questionnaire randomly sent to both staff and students was used to elicit relevant information for the study. A total of 260 individuals responded to the questionnaire. Data from the clinic medical data base (Care plus) was used to ascertain the incidence of Malaria from January 2014 to June, 2016. Using line graph, percentage distribution table, mean and standard deviation for data analysis, findings from the study indicated an overall rise in the incidence of malaria. The mean and SD value of $56.7 \pm 35.2$ showed that individuals varied in their choice of preventive/control method for malaria infection. Most respondents $47.3 \%$ and $40 \%$ would prevent malaria attacks by using insecticide spray and screening of doors and windows respectively. $23.1 \%$ of the respondents drain stagnant water (breeding site for mosquitoes) or use prophylactic malaria drug (22.7\%). Less than $15 \%$ would use either of various other methods such as treated mosquito nets, clearing of surrounding bushes and grass, repellent creams, wear protective clothing or use mosquito coil/bat (5.8\%). Based on the perceived factors which influence individual choice of adopting variety of methods to prevent malaria attack, $45 \%$ of the respondent reported lack of awareness as a major factor influencing malaria controls strategy and Location/Environment (36.9\%), inefficient/incorrect use of preventive measures (30.4\%). 20\% considered cost, safety level of repellent, nets, insecticides and chemical/drug resistance as a factor with educational level perceived as been the least influential (16.9\%). The study identified a lax in attitude and inefficient utilization of available resources. Therefore, it is imperative for every individual to be more proactive and conscientious in their approach towards the prevention and control of malaria infection. Heightened malaria awareness program as a way of public enlightenment synergized by enabling policies and strategic planning at specific periods of the year will go a long way in mitigating the incidence of malaria and the ripple effect it has on the nation.
\end{abstract}

Keywords: Malaria, Incidence, Control, Preventive Measure, Factors, University

\section{Introduction}

Malaria is a major health problem in Nigeria where it accounts for more cases and death than any other country in the world with $97 \%$ of the population at risk for the infection. As the world marked the world malaria day, the United States said, an estimated 100 million cases and about 300,000 deaths are recorded each year in Nigeria [1]. Malaria is a mosquito-borne infectious disease caused by parasitic protozoan belonging to the plasmodium type. A debilitating and life threatening illness which has been described as an entrenched global health challenge, endemic in over hundred countries in the world with approximately half of the world's population at risk of the infection $[2,3]$.

The presence of malaria in an area requires a combination of high human population density, high mosquito population density and high rates of transmission from humans to 
mosquitoes and from mosquitoes to humans. If any of these is lowered sufficiently, the parasite will eventually disappear from that area, as happened in North America, Europe and much of the Middle East. Methods used to prevent malaria include medications, mosquito eradication and the prevention of bites. However, unless the parasite is eliminated from the world, it could become re-established if conditions revert to a combination that favors the parasite's reproduction [4]. The World Health Organization (WHO), has in the last 30 years, through various avenues, such as the roll back malaria initiatives, governmental and non-governmental organization, contributed immensely towards the eradication of malaria through provision of drugs, treated mosquito nets, insecticides, support fund, creating awareness and training on malaria and malaria control. However, the problem has returned a hundred fold particularly in Nigeria [5]. In 2008, the United Nation set a more ambitious objective: to halt malaria deaths by ensuring universal coverage of malaria interventions by 2010 [6]. The aim was to make indoor residual spraying (IRS), chemoprophylaxis, elimination of breeding sites and long-lasting insecticidal nets (LLINS) available to all people at risk of malaria, especially children and pregnant women in Africa, and for all public health facilities to be able to provide reliable diagnosis and effective treatment for malaria [7].

Today, the increasing incidence and the huge economic burden of Malaria in all strata of Nigeria's educational system is becoming alarming and should agitate the mind of every meaning individual, parents, policy makers, and administrators and so on. At the university and community level, the human and economic costs associated with declining quality of life, consultations, treatments, hospitalization, time loss, low performance in daily activity and other events related to malaria are enormous and often lead to low productivity and loss of income. Among the school students, malaria is the most common cause of outpatient visit, responsible for school absenteeism, poor academic performance, examination failure, school dropouts and even death in severe and untreated cases [8, 9, 10, 11].

The study conducted by Adeyemo, Makinde, Chukwuka with Oyana (2013) investigated the incidence of Malaria infection amongst undergraduates of the University of Benin (UNIBEN), Edo State, Nigeria. The study utilized a retrospective descriptive design to analyze patients' records from June 2010 to May 2013. The checklist included information on frequency of attendance relating to malaria, drugs used for treating malaria in the health center for the years studied and frequency for admitted and referral cases. The result from the analysis revealed that there was an upward shift in occurrence of malaria in the first year and more in the second year studied, which implies that the incidence of malaria among the students who visited the health Centre was on the increase [12].

In a study Conducted by Okwa, Sanyaolu with Olatokunbo (2012) on the effect of malaria on the working performances of randomly selected Academic Staff (A.S.) of the Lagos State University (LASU), Nigeria. Structured questionnaires were administered to randomly selected A.S. comprising of 40 Females and 50 Males. Unstructured questionnaires were administered to 10 Staff Doctors (S.D.) as a second exploratory approach. The results indicated that for both gender, the history of the frequency of illness, time loss, hospital admission were similar. Similarly, inefficient delivery of lectures was the most reported adverse effect and Insecticide Treated Nets (ITNS) were the best preventive measure. However, differences existed in methods of seeking treatment, drug use and amount spent on malaria between genders. Staff doctors reported that an average of 21 A.S. visited the health centre daily of which 17 (81\%) are often diagnosed for malaria, while $6(1.1 \%)$ may be admitted monthly, more Female staff $(76.1 \%)$ reported than Male staff. They also asserted that malaria affects and impacts even on some highly educated people with adequate knowledge of Malaria [9].

Ojuroungbe, Ishola with Ojurongbe (2014) studied the perception and treatment practice of Malaria among tertiary institution students in Oyo and Osun states, Nigeria. The study observed that the respondents are aware of the common symptoms of malaria. Most (81\%) of the students are aware that mosquito bite could result into malaria infection. Surprisingly, very few $(14.6 \%)$ believed that dirty environment could cause malaria and the knowledge (23.4\%) and the use $(22.1 \%)$ of insecticide treated bed net was low in the studied population [12].

To determine the malaria prevention practices of school adolescents in the coastal community of Calabar, Nigeria, Udonwa, Gyuse with Etokidem (2010) in a cross-sectional survey involving secondary schools in southern Calabar examined four hundred adolescents were randomly selected from the 4565 learners in 5 out of 17 secondary schools in southern Calabar, Cross River State, Nigeria. A selfadministered, semi-structured questionnaire was administered to the respondents. The result showed that most respondents $(77.5 \%)$ were aware that the vector transmits the malaria parasite through biting. Fewer respondents would prevent malaria attacks by clearing the vegetation in the peridomestic environment $(13.5 \%)$, filling up potholes $(16.9 \%)$, opening up drainage (11\%), using insecticide-treated nets $(25.7 \%)$ or using antimalarial drugs $(11.2 \%)$. Less than onetenth $(8 \%)$ would use other methods such as not accepting unscreened blood [8].

The university management in her effort to control malaria infection which account for more illness cases than any other medical condition among her members has developed several malaria control measures such as proper refuse disposal and recycling, mechanized clearing of surrounding bush, construction of drainage systems and fumigation of hostels and quarters. Despite these measures more cases of malaria are being reported at the university clinic [13].

Myriads of other studies or literature are on ground, giving reports of malaria incidence and prevalence all over the country and world over. But it is important to note that, a risk assessment is of no value, if the results are not acted upon. This study is poised to determine the incidence of malaria 
and its control strategies among members of American University of Nigeria community.

\subsection{Objectives of the Study}

The general Objective of this study is to investigate the Malaria control strategy among members of American University of Nigeria Community. However, the specific objectives include:

a) To determine the incidence of malaria among American University of Nigeria Community based on the clinic record.

b) To determine the malaria control strategy among members of AUN community.

c) To ascertain the specific factors which tend to impede the effective implementation of malaria control strategy.

\subsection{Scope of Study}

The study was limited to staff and students with operational email address.

\section{Methodology}

\subsection{Study Design}

In other to ascertain the individual control strategies among members of American University of Nigeria (AUN) Yola, the study utilized a comparative descriptive survey design.

\subsection{Target Population and Study Area}

The study area (AUN) has a population of about 2000 comprising of both staff and students. All students and staff during their orientation are assigned an official email account, available at the communication center under the auspice of the human resource department. The campus occupies nearly 1000 hectares, a mixture of desert and farmlands. Located in the northeastern part of Nigeria, the area lies between $9^{\circ} 20^{\prime} \mathrm{N}$ and $12^{\circ} 30^{\prime} \mathrm{E}$ within the north Guinea savannah and sub Sudan zone. The area, therefore, experiences a wet season from May to October and a dry season from November to April every year. Although the with very high rainfall variation, the vegetation at certain periods of the year creates a favorable sites for female anopheles mosquitoes. This is probably why the prevalence of malaria is so high in the area.

\subsection{Instrument, Data Collection and Procedure}

An internet base self-structured questionnaire based on the literature review, with a reliability coefficient of 0.97 , structure and content validity, was used to elicit information on the socio-demographic data, individual malaria control strategies, factors which impede the effective implementation of malaria control strategies and individual recommendation for effective control of malaria. The online survey was sent to all staff and student to which 260 results was obtained. Primary data from Care Plus (an internet based medical software in which all outpatient and inpatient's medical test and treatment record are documented) was used to ascertain the incidence of Malaria from January 2014 to June, 2016.

\subsection{Method of Data Analysis}

Collected data were presented using line graph and tables. Descriptive statistics such as frequency, percentage distribution, mean and standard deviation were used for data analysis with the aid of Microsoft excel.

\subsection{Ethical Consideration}

The study was approved by the AUN ethical review committee. Consent was sought from the respondents and all information provided was treated with utmost confidentiality.

\section{Results}

\section{Personal Information}

A total of 260 individuals responded to the online questionnaire as shown on Table 1 below. On the whole, most of the respondents were females $(56.9 \%)$ while males were (43.1\%). Across the five age groups, 16-20, 21-25 were majority with $27.3 \%$ and $20.4 \%$ respectively, while $26-30,31$ 35 with 40years and above were basically within the range of 14 to 16.9 percent and $36-40$ had the least number of respondents with $6.2 \%$. 65.4\% are singles (65.4\%), 32.7\% married, $1.1 \%$ divorced and $0.8 \%$ widowed. Graduate and postgraduate respondents constituted exactly $71 \%$ respondents while secondary educated respondents accounted for $26.5 \%$, primary education, $0.4 \%$, No formal education $2.3 \%$.

Table 1. Personal Data.

\begin{tabular}{lll}
\hline Sex & Frequency & Percentage \\
\hline Male & 148 & 56.9 \\
Female & 112 & 43.1 \\
Total & 260 & 100 \\
Age Groups & Frequency & Percentage \\
$16-20$ & 71 & 27.3 \\
$21-25$ & 53 & 20.4 \\
$26-30$ & 37 & 14.2 \\
$31-35$ & 39 & 15.0 \\
$36-40$ & 16 & 6.2 \\
41 and above & 44 & 16.9 \\
Total & 260 & 100 \\
Marital Status & Frequency & Percentage \\
Single & 170 & 65.4 \\
Married & 85 & 32.7 \\
Divorced & 3 & 1.1 \\
Widowed & 2 & 0.8 \\
Total & 260 & 100 \\
Education Q & Frequency & Percentage \\
None & 6 & 2.3 \\
Primary & 1 & 0.4 \\
Secondary & 69 & 26.5 \\
Graduate & 103 & 39.6 \\
Post graduate & 81 & 31.2 \\
Total & 260 & 100 \\
\hline
\end{tabular}

The Figure 1 below compares the change in Malaria incidence in AUN community from January 2014 to August, 2016. The overall trend created between the three lines shows 
a general rise in the incidence of malaria. The trend across the different months of the year exhibits similar change pattern marked with sharp rise and fall in the incidence rate.

Based on the months of the year, the incidence of malaria was seen to be highest between September and November but peaks in October (about 110 and 140 in 2014, 2015 respectively). December to August is characterized with a lot of rise and fall in the malaria cases. A significant rise was seen in February with about 63 and 90 cases registered in 2014 and 2015 respectively and about 110 cases in March, 2016.

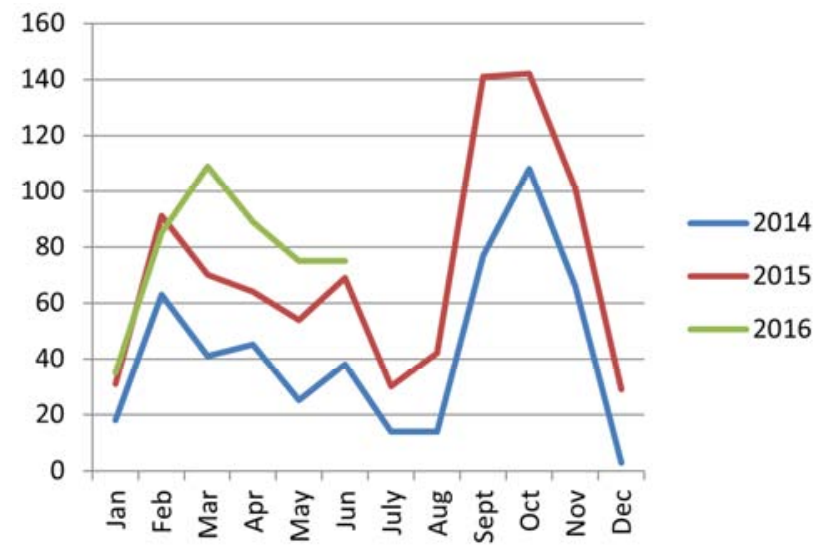

Figure 1. Showing the Incidence of Malaria in AUN between 2014 to Midyear 2016.

Table 2. Showing the Percentage Distribution of Individual Measures taken to Prevent Malaria Infection $N=260$.

\begin{tabular}{lll}
\hline Preventive Measures & Frequency & Percentage \\
\hline Spraying insecticides & 123 & 47.3 \\
Screening of windows/doors & 104 & 40 \\
Draining Stagnant water & 60 & 23.1 \\
Use of Antimalarial Drug & 59 & 22.7 \\
Use of Treated nets & 38 & 14.6 \\
Sanitation/Clearing Vegetation & 38 & 14.6 \\
Use of Repellent Cream & 38 & 14.6 \\
Wearing Long cloths & 35 & 13.5 \\
Use of Coil/Bats & 15 & 5.8 \\
Mean Value & 56.7 & \\
Standard Deviation & 35.2 & \\
\hline
\end{tabular}

NB: Table has multiple options

The mean and standard deviation of $56.7 \pm 35.2$ from the data on Table 2 indicates that the respondents varied in their choice of preventive/control method for malaria infection. Majority of the respondent uses insecticide spray and screening of doors and windows as a major preventive strategy from mosquito attack with $47.3 \%$ and $40 \%$ respectively, while the use of mosquito coil and bats was the least method used with $5.8 \%$. $23.1 \%$ of the respondents drain stagnant water (breeding site for mosquitoes) and $22.7 \%$ use prophylactic malaria drug as a preventive measure. $14.6 \%$ of the respondents use treated mosquito nets, $14.6 \%$ use sanitation (clearing of surrounding bushes and grass) and $14.6 \%$ use repellent creams while $13.5 \%$ wear protective clothing especially at night.
Table 3. Showing the Percentage Distribution of Factors influencing Individual Choice of Preventive Measures for Malaria $N=260$.

\begin{tabular}{|c|c|c|}
\hline Factors & Frequency & Percentage \\
\hline Lack of awareness & 117 & 45 \\
\hline Environment and location & 96 & 36.9 \\
\hline $\begin{array}{l}\text { Incorrect or inefficient use of } \\
\text { malaria preventive strategies }\end{array}$ & 79 & 30.4 \\
\hline $\begin{array}{l}\text { Increasing resistance to chemicals } \\
\text { and insecticides by mosquitoes }\end{array}$ & 54 & 20.8 \\
\hline Cost & 52 & 20 \\
\hline $\begin{array}{l}\text { Increasing resistance to malaria } \\
\text { drugs }\end{array}$ & 52 & 20 \\
\hline $\begin{array}{l}\text { Safety level of insecticides, sprays, } \\
\text { or treated nets }\end{array}$ & 52 & 20 \\
\hline Educational level & 44 & 16.9 \\
\hline Mean Value & 68.25 & \\
\hline Standard Deviation & 26.31 & \\
\hline
\end{tabular}

Table 3 depicts the perceived factors which influence individual choice of adopting variety of methods to prevent malaria attack. On the whole, $45 \%$ of the respondent report lack of awareness as a major factor for malaria controls strategy, followed by factors springing from Location/Environment and inefficient/incorrect use of preventive measure with $36.9 \%$ and $30.4 \%$ respectively. $20 \%$ considered cost, safety level of Chemical containing methods (sprays, nets, insecticides) and chemical/drug resistance as a factor while educational level was least perceived as been influential in malaria control measure with $16.9 \%$.

\section{Discussion of Findings}

Our study finding showed an overall rise in the incidence of malaria over the time period. This finding agrees with the work of Adeyemo, Makinde, Chukwuka with Oyana (2013) in which the incidence of malaria among students of University of Benin that visited the health center was on the rise. From the Line graph the incidence of malaria cases peaks between August and November and coincides with the resumption of new academic session into the University community. The spike in the incidence shows similar pattern in 2014, 2015. For 2016, the trend in the first half of the year shows similar flow pattern but with higher number of cases. Adequate strategic and time focused preparation should be made, awareness created, policies instituted and individual/students support groups formed to mitigate the possible spike in the number of malaria cases before August.

Based on the Individual preventive measures adopted by members of AUN community to augment the management effort in her fight against malaria, the result in Table 2 shows that the individual attitude towards malaria prevention is lax which accounts for the overall rise in number of malaria cases. The analysis of the identified methods using mean and standard deviation $(56.7 \pm 35.2)$ showed that, although the respondents varied in their choice of preventive/control method for malaria infection, less than $15 \%$ of the respondent uses Treated mosquito nets wear protective clothing especially at night and/or clear surrounding vegetation which 
but encourage feasting/breeding of mosquitoes. $30-45 \%$ of the respondent's preventive measures centered on screening of doors and windows and spraying of insecticides. This finding is incongruent with the finding of Okwa et al (2012) in which Treated nets was identified as the major preventive method. It is therefore suggested that more effort should be made on enlightening individuals on the use of treated nets and healthful living practices that discourage the breeding of mosquitoes in the environment.

Findings from the data analyzed in line with the third objective which sought to ascertain the factors which influence individual choice of preventive measures for malaria as shown in table 3 , reveals that about $30-50 \%$ of the respondents believes that lack of awareness, environment and inefficiency related factors informs their choice. This finding disagrees with the study of Ojuroungbe et al (2014) in which respondents' demonstrated good knowledge of malaria cause but poor understanding of predisposing factor like environment. $20 \%$ of the respondent identified cost, safety level of chemically based methods which necessitate creating more awareness on the safety and efficacy of chemical based methods such as treated nets, sprays, repellants, and insecticides and the proper method of utilization to ensure its effectiveness in protecting individuals' against mosquito bites.

\section{Conclusion}

The study identified a lax in attitude towards malaria control. All successful preventive/control measures for malaria infection requires a form of behavioral change, failure of which is evident in the steady rise in the incidence of malaria infestion with it concomitant economic and social cost in terms of low productivity, low academic performance, loss of income, time loss, absenteeism and so on. Although Malaria has become a household name, yet the increasing incidence is a cause for alarm and raises the need to reevaluate individual and community effort geared towards prevention of malaria. In lieu of this, it is imperative for every individual to be more proactive and conscientious in their approach towards the control of malaria infection. To ensure a more enabling learning and working environment, management and resident directors should make room for individuals to participate in the prevention of malaria among her populace. These can be achieved by formation and organization of Malaria Awareness Club and programs as a way of public enlightenment on the prevention and control of the disease among her community. Furthermore, review of policies which hinder individuals from efficiently utilizing malaria prevention resources at their disposal such as the use of treated nets can be revised.

\section{Acknowledgement}

The authors are grateful to the management and staff of the American University of Nigeria Clinic for providing the Primary data and securing approval for the study. Special gratitude also goes to Dr Nwankwo Ukamaka for reviewing this paper.

\section{References}

[1] United State Diplomatic Mission, "Nigeria Malaria Fact Sheet 2011". Retrieved on 7th July, 2016 from http://www.nigeria.usembassy.gov.

[2] S. H. Nyarko and A. Cobblah "Sociodemographic determinants of malaria among under five Chidren in Ghana," Malaria Research and treatment. 2014. Retrieved on 7th July, 2016, from http://www.hindawi.com/journals/mrt.

[3] World Health Organization (2016) "Malaria Fact Sheet". Retrieved on 7th July, 2016 from http://www. Who.int/mediacentre/factsheets/.

[4] World Health Organisation (2010) "Malaria". Retrieved on July 8, 2016 from http://www.en.wikipedia.org.

[5] Gale Encyclopedia of Medicine "Malaria", 2016.

[6] E. Oluwana and O. Ogunsusi "Impact of Malaria on productivity and coping strategies among small scale garri processors in Odeda Local Governmnet Area of Ogun State, Nigeria," African Journal Online. Vol. 1 (2), 118-129. 2007. Retrieved on 6th July, 2016 from http://www.ajol.info/index.phla/view/41003.

[7] F.O. Adeyemo, O. Y. Makinde, L. O. Chukwuka and E. N. Oyana "Incidence of Malaria among the undergraduates of University of Benin, Benin City, Nigeria," Internet Journal of Tropical Medicine. Vol 9(1). 2013. Retrieved on 7th July, 2016, from http://www.ispub.com.

[8] N. E. Udonwa, A. N. Gyuse and A. J. Etokidem "Malaria: knowledge and prevention practice among school adolescents in a coastal community in Calabar, Nigeria," African Journal of Primary Health Care and Family Medicine. Vol 2(1). 2010. Retrieved on 7th July, 2016, from http://www.phcfm.org/index.php/phcfm.

[9] O. Okwa, L. Sanyaolu and A. F. Olatokunbo "Malaria and working performance of academic staff in Nigerian University," Research Journal of Biology. Vol 2(5), 151-156, 2012. Retrieved on 3rd August, 2016 from http:// www.scientific-journals.co.uk.

[10] O. Omalade, B. Babatunde and S. Olundegun "Social aspect of Malaria among two tertiary institutions in Lagos State," Sierra lone Journal of Biomedical Research. Vol (3) 2, 97103. August, 2011. Retrieved on July 8, 2016 from http://www.ajol.info/journal.

[11] World Health Organisation "World Malaria Report”, 2011. Retrieved on July 8, 2016 from http://www.who.int/chp/topics.

[12] T. Ojuroungbe, I. Ishola and O. Ojurongbe "Perception and treatment practice of Malaria among tertiary institution students in Oyo and Osun States, Nigeria," Journal of Natural Science Research. Vol 4(5), 33-42, 2014.Retrieved on 3rd August, 2016 from http://www.iiste.org.

[13] American University of Nigeria "AUN clinic medical data base" 2016. Retrieved on 7th July, 2016, from http:// www.aun.edu.ng. 